\title{
A Saúde da Mulher e a Tecnologia: Uma Análise Heurística e Netnográfica do Aplicativo Clue
}

\author{
Kalissa Rodrigues \\ PUCRS, Escola Politécnica \\ Porto Alegre, Brasil \\ kalissa.castro@acad.pucrs.br
}

\author{
Larissa Salerno \\ PUCRS, Escola Politécnica \\ Porto Alegre, Brasil \\ larissa.salerno@acad.pucrs.br
}

\author{
Luiza Johnstone \\ PUCRS, Escola Politécnica \\ Porto Alegre, Brasil \\ luiza.johnstone@acad.pucrs.br
}

\author{
Mayara Jesus \\ PUCRS, Escola Politécnica \\ Porto Alegre, Brasil \\ mayara.jesus@acad.pucrs.br
}

\author{
Milene Silveira \\ PUCRS, Escola Politécnica \\ Porto Alegre, Brasil \\ milene.silveira@pucrs.br
}

\section{RESUMO}

Com a difusão de aplicações para apoio a cuidados pessoais e a propagação do ciberfeminismo e do ativismo digital, surgem tanto aplicativos voltados à saúde da mulher quanto ciberespaços voltados ao tema. Neste cenário, avaliamos o Clue, um aplicativo para monitoramento de controle menstrual, o qual, além de ser bem avaliado nas lojas de apps, como a App Store e o Google Play, também conta com usuárias assíduas as quais utilizam grupos para discorrer sobre o funcionamento deste e dos assuntos que o aplicativo aborda (ciclo menstrual, período fértil, etc). Para esta avaliação, foi aplicado o método de Avaliação Heurística e realizado um estudo etnográfico online (Netnografia) sobre discussões pautadas sobre o tema em um grupo específico do Facebook. Foi constatado que a aplicação possui poucos problemas de usabilidade considerados catastróficos, porém existe uma quantidade considerável de usuárias que relatam dificuldades no manejo de algumas de suas funcionalidades.

\section{Palavras-chave}

Cuidados pessoais, ciberfeminismo, controle menstrual, Avaliação Heurística, Netnografia.

\section{INTRODUÇÃO}

É notório que a tecnologia está presente na vida cotidiana da grande maioria da população e que, na atualidade, ela está presente inclusive nos cuidados com a saúde. Cada vez mais são difundidas aplicações que tem como propósito facilitar os cuidados pessoais, seja através de lembretes para

\footnotetext{
Permission to make digital or hard copies of all or part of this work for personal or classroom use is granted without fee provided that copies are not made or distributed for profit or commercial advantage and that copies bear this notice and the full citation on the first page. Copyrights for components of this work owned by others than the author(s) must be honored. Abstracting with credit is permitted. To copy otherwise, or republish, to post on servers or to redistribute to lists, requires prior specific permission and/or a fee. Copyright 2018 SBC.
}

IHC 2018, Anais Estendidos do XVII Simpósio Brasileiro sobre Fatores Humanos em Sistemas Computacionais

Outubro 22-26, 2018, Belém, Brasil

Competição de Avaliação - Graduação beber mais água, seja para cuidados mais íntimos.

Uma área que tem sido explorada com essas aplicações é a da saúde da mulher pois, com a propagação da quarta onda feminista (ciberfeminismo) e o ativismo digital, tem-se um empoderamento feminino mediado pelas redes e pela internet. Segundo Rocha [6], o ciberfeminismo compreende-se tanto pela inserção/participação de ativistas do movimento social feminista, quanto por pessoas que não detêm conhecimento prévio acerca da temática. E, de acordo com Ferreira [2], os ciberespaços feministas objetivam atrair mais jovens e desconhecedores da causa, esclarecendo temas e conceitos do movimento.

Assim sendo, assuntos relativos à sexualidade feminina estão cada vez mais em voga, e, tendo em vista que o organismo feminino é afetado pelo ciclo menstrual o tempo todo, seja influenciando no humor, na libido ou, até mesmo, na sensibilidade, os aplicativos desta área não só auxiliam no entendimento corporal e nas influências do ciclo menstrual sobre o corpo, mas também geram tópicos de discussão em diversos canais, como grupos de Facebook e Whatsapp.

Neste cenário, o trabalho desenvolvido buscou analisar as discussões sobre aplicativos de saúde da mulher em um grupo feminino no Facebook e, também, explorar de forma aprofundada uma destas aplicações. A partir desta análise inicial, houve a seleção do aplicativo Clue, sobre o qual foram feitas análises de usabilidade através da aplicação do método de Avaliação Heurística, assim como uma pesquisa qualitativa sobre tópicos do grupo, caracterizando um Estudo Netnográfico.

Para compreensão do trabalho realizado, na segunda seção é descrita a metodologia que foi utilizada, na terceira o detalhamento da avaliação realizada, com a aplicação da Avaliação Heurística e da Netnografia, na quarta seção uma discussão sobre os resultados obtidos e, por fim, na última 
seção são apresentadas as considerações finais deste estudo, seguidas pelas referências utilizadas em sua elaboração.

\section{METODOLOGIA}

Para realização deste trabalho, primeiro foi feita uma análise de aplicativos disponíveis para cuidados com a saúde da mulher, assim como um breve levantamento sobre os mais usados dentre as participantes do grupo de Facebook utilizado na etapa de análise netnográfica, e escolhido o aplicativo a ser avaliado. Após, foram aplicados os métodos de Avaliação Heurística e a Netnografia. Por fim, foi realizada uma discussão acerca dos resultados obtidos e métodos utilizados.

A Figura 1 apresenta estas fases, as quais serão descritas nas subseções a seguir.

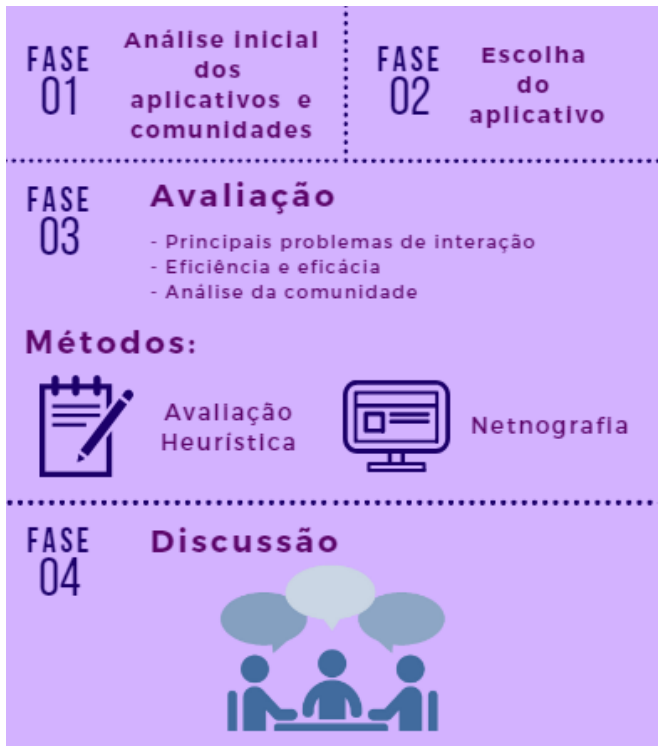

Figura 1. Metodologia adotada.

Fase 01- Análise Inicial dos Aplicativos e Comunidades Tendo em vista explorar os diferentes aplicativos existentes de saúde para a mulher, o grupo decidiu por focar em aplicativos para controle de ciclo menstrual. Fez-se uma análise sobre as avaliações disponíveis em lojas de aplicativos, como a App Store e o Google Play, assim como sobre quais aplicativos eram melhor avaliados em grupos femininos no Facebook.

Quanto à análise das comunidades, esta será descrita em detalhes quando da descrição da aplicação da Netnografia.

\section{Fase 02- Escolha do Aplicativo}

Escolheu-se então, dentre as aplicações com mais de 4 estrelas no Google Play e na App Store (Figura 2), o Clue, por ser um dos mais comentados no grupo, com diversas discussões relevantes sobre seu manuseio, e também, por ter uma interface bastante intuitiva mas com alguns pontos a serem ressaltados e possivelmente melhorados, conforme relatos no grupo.

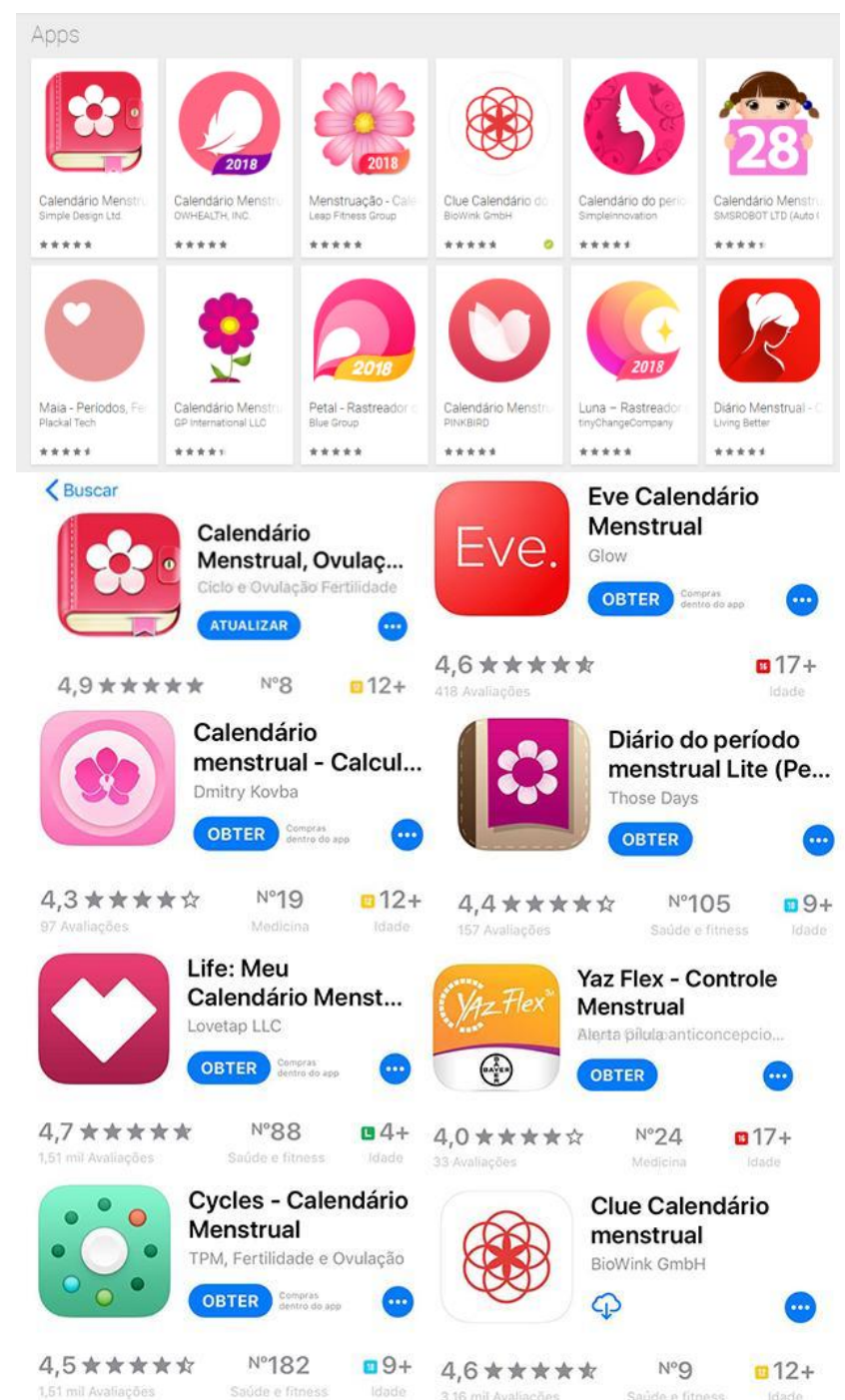

Figura 2. Aplicativos para controle menstrual analisados na Google Play e App Store.

O aplicativo Clue ${ }^{1}$ tem como objetivo monitorar o ciclo menstrual, lembrando as usuárias sobre as datas de sua menstruação, período fértil e até mesmo sobre o início e fim de seu período de TPM (Tensão Pré-Menstrual). O Clue não apenas serve como um calendário da saúde feminina, mas também possibilita armazenar informações sobre relações sexuais, dores, secreções, controle de métodos contraceptivos e temperatura corporal, auxiliando a encontrar padrões durante seu ciclo menstrual.

Dentre os aplicativos de controle de ciclo menstrual disponíveis, o Clue possui uma interação simples e um padrão de interface que foge do tema rosa floral dos demais, o que acaba por causar uma maior adesão ao mesmo. Foi escolhido por sua relevância comprovada nos

\footnotetext{
${ }^{1}$ https://play.google.com/store/apps/details?id=com.clue.and roid\&hl=pt_BR
} 
nos fóruns analisados, assim como por sua avaliação nas lojas de aplicativos, conforme descrito anteriormente.

\section{Fase 03- Avaliação}

Para avaliação foram escolhidos dois métodos: a Avaliação Heurística e a Netnografia. A escolha desses métodos se deu por dois motivos principais: (1) investigar se os tipos de problemas encontrados por ambos seriam complementares ou se seriam encontrados novos problemas relatados por seus usuários, em seu dia a dia de uso; (2) estudar um método (Netnografia) que não é comumente trabalhado em atividades de sala de aula e, assim, aprofundar os estudos na área de avaliação de IHC (Interação Humano-Computador).

\section{Avaliação Heurística}

A Avaliação Heurística é uma ferramenta de inspeção de usabilidade e, de acordo com Nielsen [5], é o método mais informal e comum de avaliação.

Esta avaliação tem o objetivo de verificar a conformidade do sistema com um padrão preestabelecido (conjunto de 10 heurísticas visto na Figura 3), identificando possíveis problemas na interação do usuário com o sistema e sua interface.

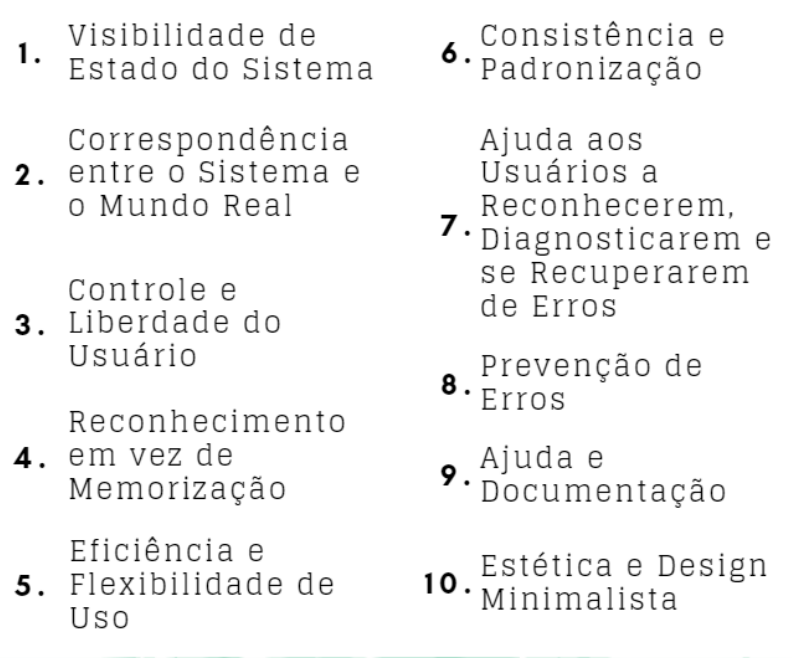

Figura 3. Heurísticas de Nielsen [4]

Sendo um método de inspeção, a Avaliação Heurística é realizada do ponto de vista de especialistas, que se colocam no lugar do usuário. São recomendados de 3 a 5 especialistas, os quais, a partir da definição da porção da interface/sistema a ser avaliada, a percorrem individualmente, inspecionando-a com base nas heurísticas anteriormente citadas. Após a finalização das avaliações individuais, o grupo de especialistas se reúne a fim de consolidar suas avaliações, elaborando uma lista única de problemas, a qual contém a descrição detalhada de cada problema encontrado, a heurística associada (ferida), o grau de severidade do problema e uma sugestão para seu redesign.

\section{Netnografia}

De acordo com Kozinets [3], Netnografia é o nome dado a um conjunto específico de práticas de pesquisa éticas e representacionais, que envolve coleta e análise de dados relacionados. A Netnografia difere de outra pesquisa qualitativa na internet pois oferece um conjunto rigoroso de diretrizes para a realização de etnografia mediada por computador, e também sua integração com outras formas de pesquisa cultural.

A Netnografia visa inserir o pesquisador no ambiente de observação, de forma que este consiga extrair, deste, informações em seu caráter "mundo real". Seis são os procedimentos da Netnografia propostos por Kozinets [3]:

- Planejamento: saber o foco da pesquisa; ler estudos relacionados; encontrar grupos online sobre o tema a ser investigado; ter contato com a comunidade online escolhida, familiarizando-se com seus membros, linguagens, interesses e práticas; obter aprovação para elaboração da pesquisa no grupo em questão.

- Entrée: pesquisador deve integrar o grupo pesquisado, de forma a agir como um membro, mas também deixando claro seu caráter investigativo. Deve participar da comunidade de forma a se habituar às interações, terminologias, etc.

- Coleta de dados: a coleta de dados netnográficos pode ter 3 abordagens: análise sobre dados históricos do grupo, ou seja, sobre informações presentes neste sem haver interação com o pesquisador; dados instigados por perguntas, isto é, quando o pesquisador cria perguntas para o grupo, e seus membros interagem; e, anotações, as quais são as observações do analista frente à comunidade, seus membros, interações e significados.

- Análise de dados: a análise de dados netnográfica é essencialmente qualitativa, e busca decompor e detalhar as informações levantadas, com um objetivo.

- Resultados: a etapa final da Netnografia consiste na análise do conjunto de dados levantados, divulgando, assim, seus resultados.

\section{Fase 04- Discussão}

Após a aplicação da Avaliação Heurística e da Netnografia, os resultados obtidos em ambas foram analisados $\mathrm{e}$ comparados pelo grupo.

\section{AVALIAÇÃO DO CLUE}

A seguir serão apresentados os passos seguidos na avaliação do Clue tanto pelo método de Avaliação Heurística quanto pela Netnografia.

\section{Aplicação da Avaliação Heurística}

A Avaliação Heurística do Clue foi realizada por três alunas de graduação, sendo uma aluna do curso de Sistemas da Informação e duas do curso de Engenharia de Software. Todas possuem experiência prévia com aplicação de Avaliação Heurística, adquirida em disciplina da área de IHC de seu curso de graduação, e uma, em específico, ainda 
participou de um projeto de iniciação científica na área, tendo uma maior experiência na aplicação de métodos de avaliação de IHC. As avaliadoras conheceram o aplicativo recentemente e não possuíam conhecimento prévio sobre o uso do mesmo. $\mathrm{O}$ aplicativo foi utilizado por um pequeno período de tempo, durante o qual cada avaliadora individualmente - pode compreender o aplicativo e capturar as falhas de usabilidade encontradas. A avaliação foi feita com três aparelhos, sendo eles: um Iphone $5 \mathrm{~s}$ e um Iphone 7 (ambos com sistema operacional iOS) e um Moto G $3^{\text {a }}$ geração (com sistema operacional Android).

Após a consolidação dos dados, foram encontrados 13 problemas de usabilidade. A cada problema encontrado foi atribuído um grau de severidade, para que eles pudessem ser agrupados como erros cosméticos, pequenos, grandes ou catastróficos, facilitando assim, a compreensão sobre o valor real dos erros encontrados. Podemos ver, na Figura 4, um gráfico que apresenta a quantidade de erros encontrada em cada categoria.

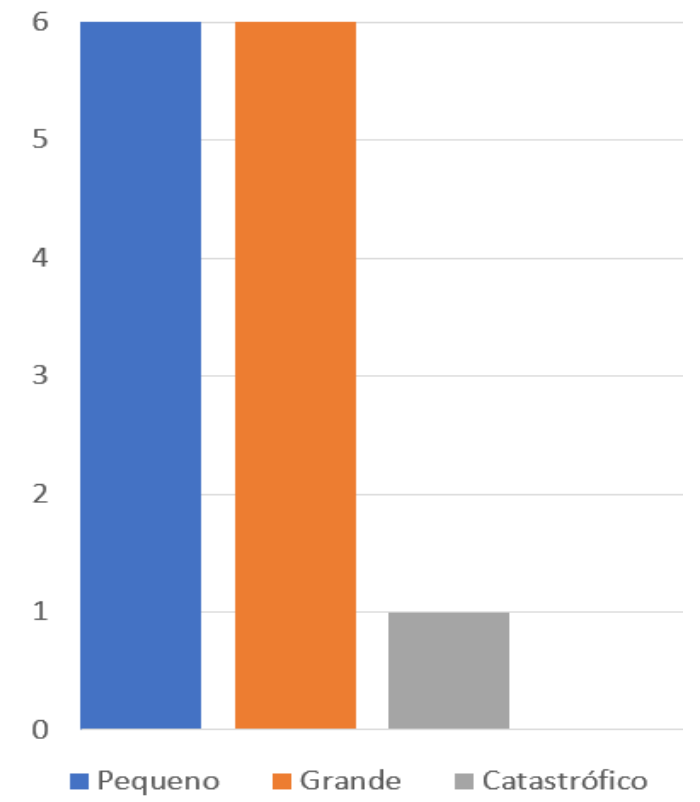

Figura 4. Gráfico da quantidade de erros por grau de severidade.

É possível perceber, pela Figura 4, que foi encontrado apenas 1 problema catastrófico, seguido pelo empate entre grandes e pequenos erros, que contabilizam 6 erros cada.

O gráfico da Figura 5 apresenta a distribuição dos problemas por heurística (o gráfico apresenta as heurísticas com nomes reduzidos para facilitar a visualização). É importante ressaltar, também, que cada problema pode violar mais de uma heurística, por isso a soma das heurísticas violadas ultrapassa o valor total de problemas encontrados. Analisando este gráfico, podemos notar que a violação de heurística mais recorrente é a de Controle e Liberdade do Usuário, o que prova que o sistema não apresenta claramente um sistema de saída para um estado indesejado em mais de uma oportunidade. A heurística de Ajuda e Documentação é a segunda mais frequentemente aplicada, mostrando que mais um problema recorrente do sistema é a falta de ajuda ou documentação sobre certos aspectos da aplicação.

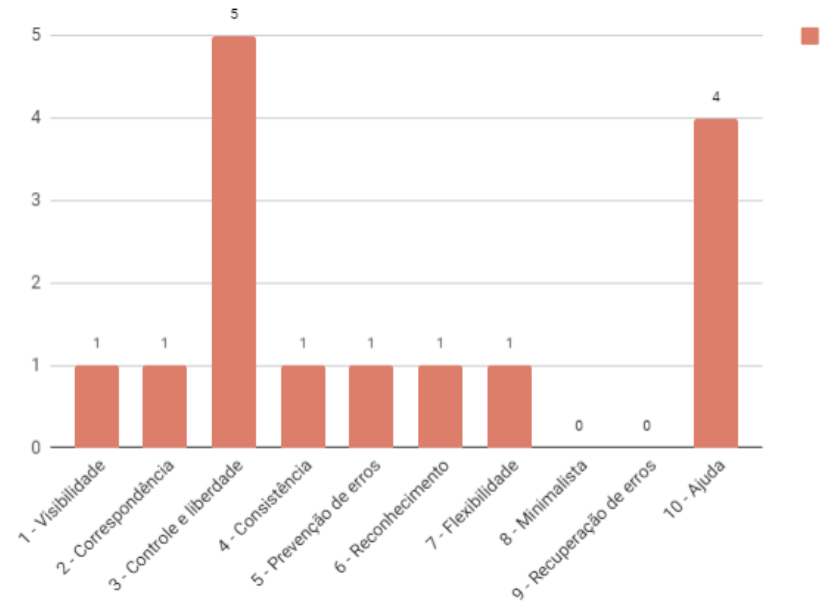

Figura 5. Gráfico da quantidade de heurísticas encontradas.

A seguir, apresentamos alguns dos problemas recorrentes que foram encontrados durante as avaliações.

Tela Inicial

Heurística Violada: Ajuda e documentação

Grau de Severidade: 3

Problema: Não existe um botão de ajuda/orientação na tela principal em qualquer momento, apenas quando é informado que houve sangramento no dia atual (Figura 6).

Heurística Violada: Visibilidade do estado do sistema Grau de Severidade: 3

Problema: Caso as informações que foram cadastradas no início da utilização do Aplicativo sejam modificadas, a figura de ciclo da tela inicial não é atualizada (Figura 6).

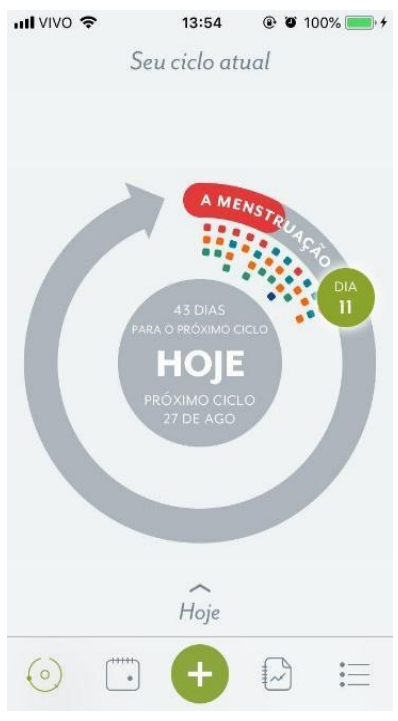

Figura 6. Tela inicial. 
Tela de Calendário - iOS

Heurística Violada: Reconhecimento ao invés de memorização

Grau de Severidade: 3

Problema: Não existe indicação de que, ao arrastar para cima, especificamente no sistema operacional iOS, as informações do dia selecionado no calendário, é possível ver em lista as informações de todo o mês. Por não haver essa informação, o usuário não sabe que há tal visualização, acreditando que é possível ver a informação de cada dia apenas quando ele está selecionado na visão "calendário" (Figura 7).

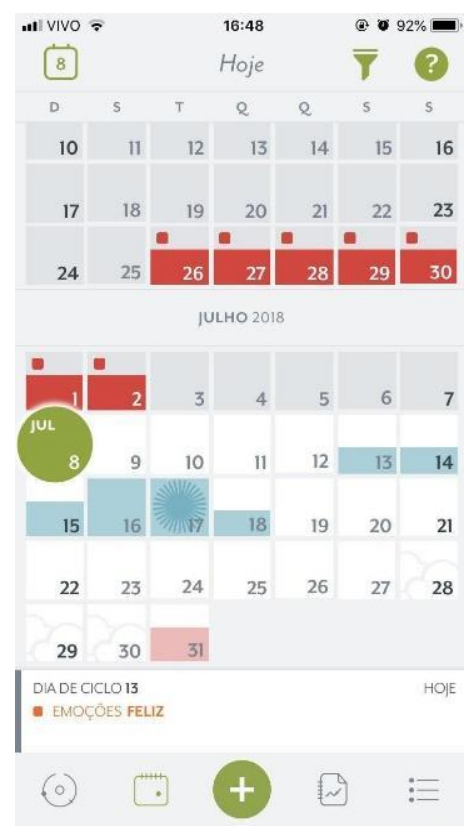

Figura 7. Calendário (iOS).

Tela de Calendário - Android

Heurística Violada: Reconhecimento em vez de memorização

Grau de Severidade: 2

Problema: O usuário do sistema pode adicionar etiquetas a cada dia da semana para descrever o dia e suas sensações, mas ao analisar o decorrer do mês, não é possível identificar o que foi selecionado a cada dia, pois as etiquetas são apresentadas como pequenos quadradinhos coloridos (Figura 8).

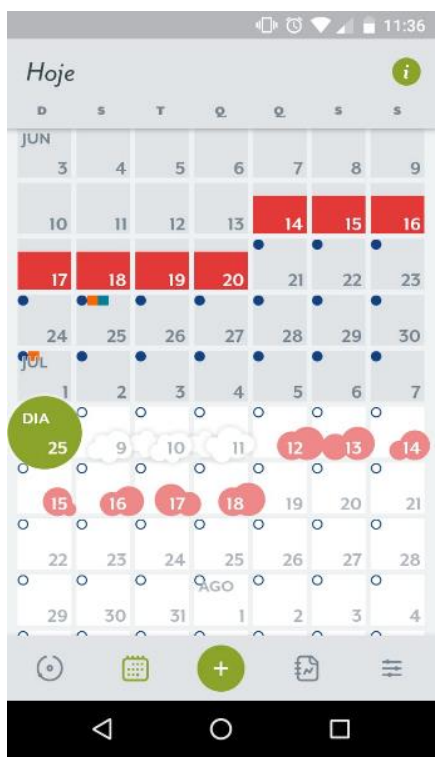

Figura 8. Calendário (Android).

Tela de Análise

Heurística Violada: Controle e liberdade de usuário Grau de Severidade: 2

Problema: Não há um botão que permita retornar à tela anterior, obrigando o usuário a deduzir que deve clicar em algum dos botões do rodapé do aplicativo (Figura 9).

Heurística Violada: Ajuda e documentação Grau de Severidade: 2

Problema: Não há uma opção para buscar ajuda ou obter informações sobre o propósito da tela no geral (Figura 9).

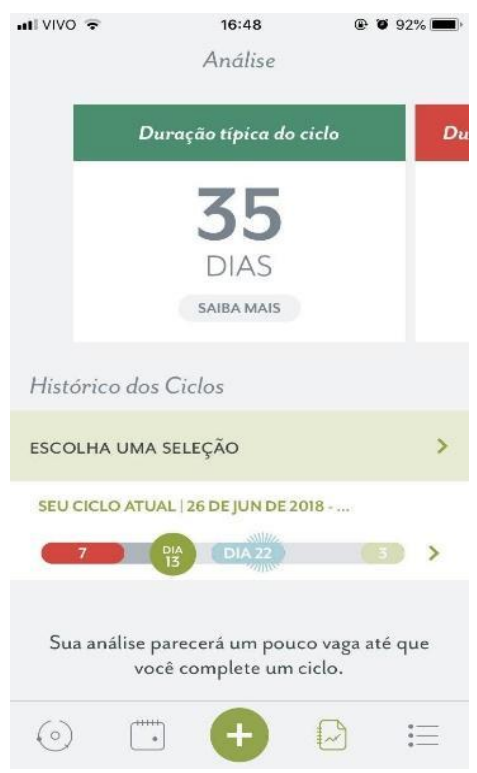

Figura 9. Tela de Análise. 


\section{Clue Connect}

Heurística Violada: Correspondência entre o sistema e o mundo real

Grau de Severidade: 4

Problema: Quando um usuário quer compartilhar o seu ciclo, ele pode gerar um código e enviar para a pessoa que poderá ter acesso a suas informações, mas quando o novo usuário tenta utilizar seu código de acesso na opção de "Adicionar o Ciclo de Alguém", o sistema apresenta uma mensagem para convidar alguém para ver o seu ciclo, sem apresentar uma opção para inserir o código enviado por outro usuário (Figura 10).

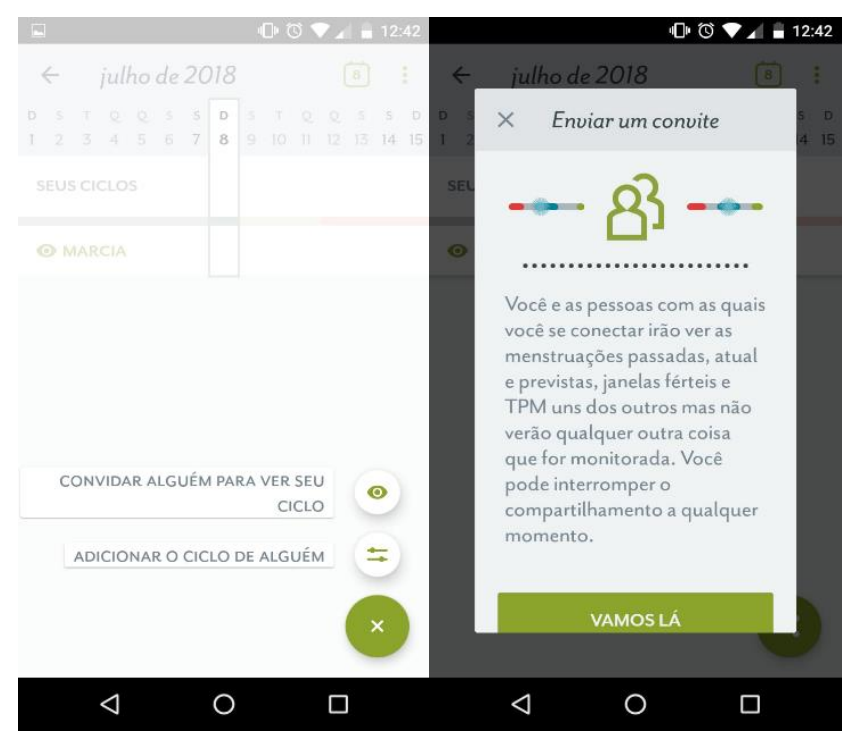

Figura 10. Clue Connect.

Heurística Violada: Correspondência entre o Sistema e o Mundo Real

Grau de Severidade: 4

Problema: Ao solicitar a opção de "Adicionar o Ciclo de Alguém", o sistema apresenta uma mensagem para convidar alguém para ver o seu ciclo, mas deveria mostrar uma tela para inserir o código enviado por outro usuário (Figura 10).

\section{Tela de Geração de Relatório}

Heurística Violada: Controle e Liberdade do Usuário

Grau de Severidade: 2

Problema: O relatório é gerado a partir do ciclo selecionado, porém, quando se deseja selecionar as entradas feitas dentro do ciclo, ele permite apenas que todas sejam incluídas no relatório, não podendo gerar o relatório de apenas uma semana, por exemplo (Figura 11).

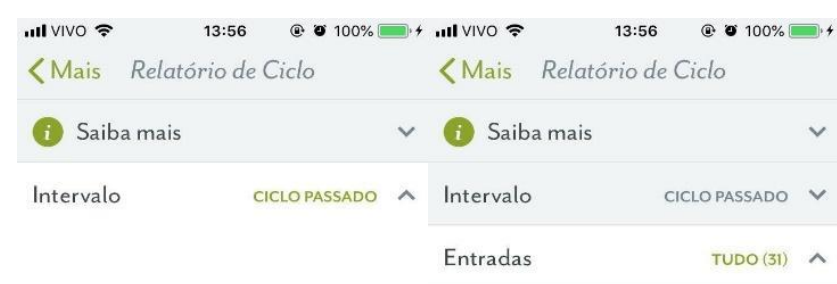

ciclo passado

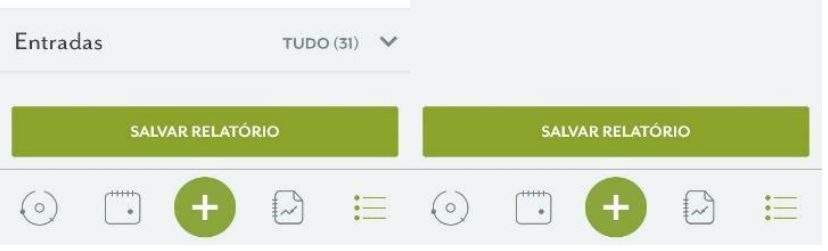

Figura 11. Geração de Relatório.

Tela de Registro de Peso

Heurística Violada: Controle e Liberdade do Usuário

Grau de Severidade: 3

Problema 1: Não há opção de voltar para a tela anterior; Problema 2: Caso o botão "Feito" seja clicado, todas as informações são salvas e não será possível cadastrar mais informações (Figura 12).

Heurística Violada: Consistência e Padronização Grau de Severidade: 3

Problema: Não há um botão no teclado numérico para registrar o peso (Figura 12).

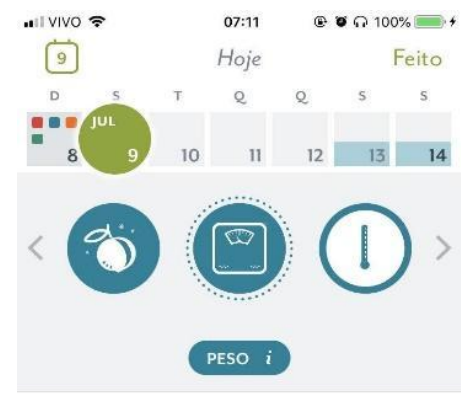

\section{$64^{\mathrm{kg}}$}

\begin{tabular}{|c|c|c|}
\hline 1 & $\underset{A B C}{2}$ & $\underset{D E F}{3}$ \\
\hline$\underset{O H I}{4}$ & $\underset{\mathrm{JKL}}{5}$ & $\underset{\text { MNO }}{6}$ \\
\hline$\underset{\text { PQRS }}{7}$ & $\underset{\text { TUV }}{8}$ & $\underset{\text { wxyz }}{9}$ \\
\hline ' & 0 & $\otimes$ \\
\hline
\end{tabular}

Figura 12. Registro de peso. 


\section{Tela de Registro de Informações}

Heurística Violada: Ajuda e Documentação Grau de Severidade: 2

Problema: Não há opção para buscar ajuda ou obter informações sobre o propósito geral da tela, apenas para cada uma das informações a ser adicionada (Figura 13).

Heurística Violada: Controle e Liberdade de Usuário Grau de Severidade: 2

Problema: Não há opção de voltar para a tela anterior, obrigando o usuário a registrar informações no dia selecionado (Figura 13).

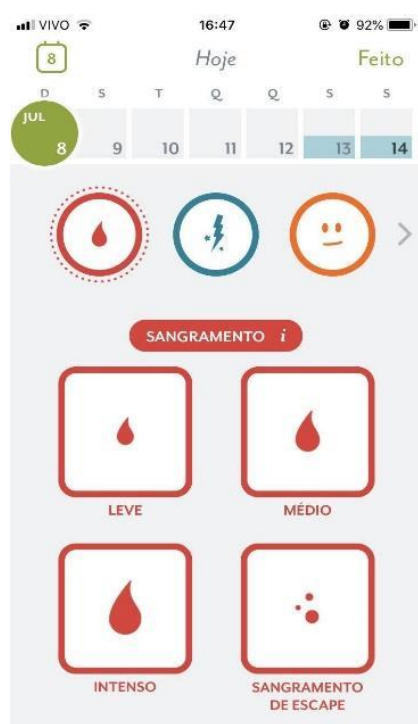

Figura 13. Registro de informações.

\section{Aplicação da Netnografia}

Tendo em vista observar pessoas em ambientes naturais, e com o intuito específico de analisar as interações de mulheres com a aplicação Clue, utilizou-se dos conceitos de Netnografia para discorrer a análise. Esta foi realizada utilizando os métodos para estudos netnográficos propostos por Kozinets [3], sendo eles os procedimentos de Planejamento, Escolha da ccomunidade e Entrée, Coleta de dados, Análise de dados e Resultados, conforme descrito na apresentação da Metodologia.

\section{Planejamento, Escolha da Comunidade e entrée}

Com o foco de investigar a utilização de aplicativos de controle menstrual, na etapa de planejamento fez-se uma seleção entre grupos do Facebook com o tema Saúde da Mulher, analisando-se quais os temas mais abordados nos grupos assim como nível de interação/contribuição das comunidades para com os levantamentos postados no fórum.

O grupo escolhido para investigação foi o "Adeus Hormônios: Contracepção Não-Hormonal", o qual conta com 136.634 membros e um histórico de publicações bastante ativo. Para a escolha, foi feito o entrée no grupo e analisado se havia quantidade significativa de postagens abordando questões referentes a aplicativos de controle menstrual e saúde da mulher, incluindo o Clue, e esta comunidade demonstrou ter quantidade de informação satisfatória para a análise, portanto esta foi a selecionada.

Por fim, foram planejadas as questões referentes a aspectos éticos, onde foi elaborada a solicitação de permissão para pesquisa netnográfica na comunidade, permissão à qual foi concedida pela moderadora do grupo (Figura 14). Após a aprovação da solicitação, deu-se andamento as etapas de levantamento de dados e análise.

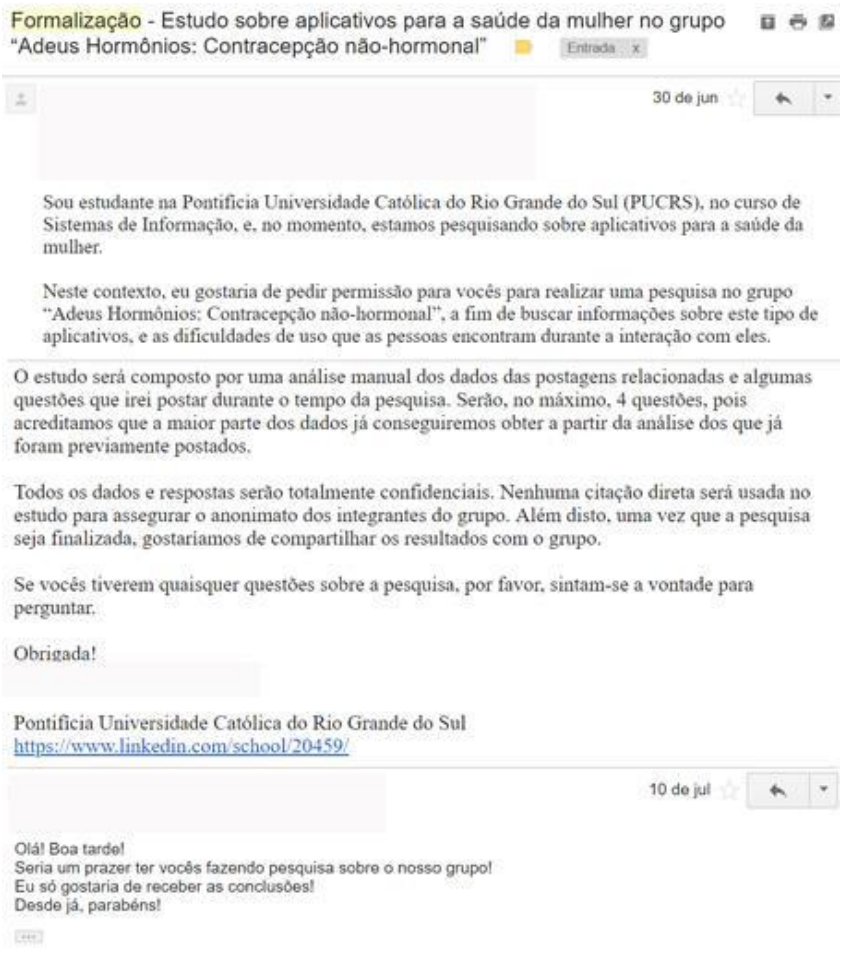

Figura 14. Aprovação da solicitação.

Coleta de Dados

Apesar de se ter autorização para coleta de dados via questões aos integrantes da comunidade, se decidiu por apenas analisar as informações históricas presentes no grupo por concluirmos já serem informação suficiente para a consolidação da análise. Para isso utilizou-se no filtro de pesquisa do fórum a palavra "Clue" e, então, buscou-se todas as postagens que tivessem o nome do aplicativo em sua descrição.

Como o foco estava na indicação de algum problema de interação pelo usuário (e não na solução deste pelos demais membros da comunidade), não foram analisadas as respostas às postagens encontradas e nem postagens em que o nome do aplicativo aparecia somente nos comentários. 
Por fim, gerou-se um arquivo com todas as postagens a partir da aplicação do filtro, levantando um total de 43 postagens.

\section{Análise de Dados}

A análise netnográfica, de acordo com Kozinets [3], envolve uma abordagem indutiva de análise de dados qualitativos. Análise significa o exame detalhado de um todo, decompondo-o em suas partes constituintes e comparando-as de diversas formas. Ainda conforme $\mathrm{o}$ autor, a interpretação faz referência à classificação, análise e posterior interpretação dos dados coletados.

Após a coleta das informações pertinentes no grupo, foi realizado o processo de análise dos dados coletados, a codificação e organização dos temas, a representação dos dados e a formulação de uma interpretação deles, de acordo com Creswell [1]. Como ferramenta para armazenamento e codificação, foi utilizado o software $\mathrm{NVivo}^{2}$.

\section{Resultados}

Ao analisar os dados históricos do grupo com a tag "Clue", foram criados códigos, conforme apresentado na Figura 15. O Nome indica o código classificado, Arquivos são quantos documentos com informações foram analisados e Referências indica quantas vezes aquele código foi citado. Os códigos que tratavam de temas não pertinentes à análise da aplicação em si, e sim de assuntos abordados tanto na comunidade quanto na aplicação, foram agrupados a fim de diminuir a complexidade. Também haviam postagens que abordavam mais de um tópico, portanto tais foram categorizadas em mais de um grupo.

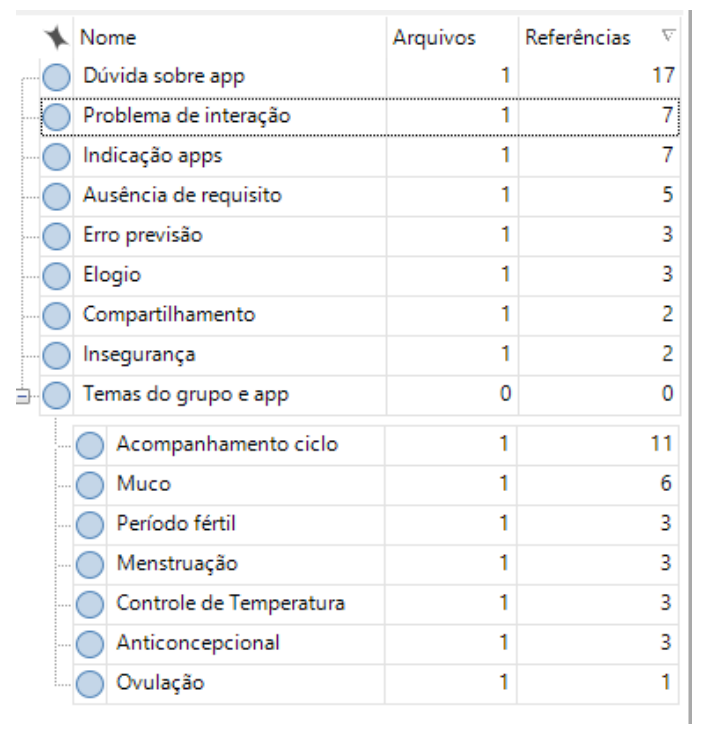

Figura 15. Classificação sobre os dados históricos.

Por conseguinte, foram geradas nove categorias, conforme segue:

\footnotetext{
${ }^{2}$ https://www.qsrinternational.com/nvivo/trial/trial-portuguese
}

- Dúvidas sobre o app: este nicho foi o mais referenciado (17 vezes) e apresentou principalmente dúvidas sobre funcionalidades do aplicativo, tais como: o que significavam algumas das siglas, como inserir informações de temperatura basal (não existia um botão para isso até a última versão - também foi notificado no código de Ausência de Requisito), qual a quantidade de ciclos necessária até ele ser mais assertivo nas previsões mensais. Foi constatado aqui que a aplicação apresenta um certo nível de complexidade, e alguma ausência de informações de ajuda.

- Problema de interação: neste grupo foram incluídas as postagens em que haviam reclamações de erros na aplicação, totalizando 7. As principais reclamações se referem a dificuldade para cadastro de informações e erro ao cadastrar, assim como problemas no calendário.

- Indicação apps: neste foram marcadas as postagens em que as participantes do fórum gostariam de receber indicações de aplicativo, porém já conheciam o Clue e o citaram na postagem. Também houveram casos de usuárias do Clue pedindo indicações de outras aplicações por não julgarem que o Clue atendeu suas expectativas e/ou relatando ausência de algum requisito (presente também na categoria de Ausência de Requisito), e de usuárias fazendo um comparativo entre o Clue e algum outro aplicativo do mesmo gênero.

- Ausência de requisito: foram observados 5 casos em que as usuárias relataram falta de funcionalidades por parte do Clue, sendo elas ausência de adaptabilidade a um ciclo maior que 28 dias (como essa, na verdade, é uma funcionalidade da aplicação, portanto tal relato também foi referenciado na categoria de Problema de interação); ausência de histórico em casos de mudança de aparelho celular; ausência de funcionalidade de alteração no calendário; ausência de botão para cadastro de temperatura basal; não possibilidade de acompanhamento, no calendário, das fases da lua.

- Erro de previsão: aqui foram incluídos os erros de previsão de menstruação e também de período fértil.

- Elogios: houveram 3 elogios ao Clue dentro das postagens analisadas, entre eles agradecendo pelos informativos que o Clue passou a enviar via e-mail e também sobre a adição de funcionalidades (botão para monitoramento do muco cervical), assim como sobre a precisão das previsões.

- Compartilhamento: houveram duas reclamações quanto à compartilhamento, porém ambas tratavam de funcionalidades diferentes: uma foi quanto ao compartilhamento do ciclo para com outro aplicativo/telefone, e outra quanto à migração de dados entre aplicativos do gênero. 
- Insegurança: houveram postagens que relataram insegurança na utilização da aplicação, tendo em vista a precisão de suas previsões. Como por exemplo, a estimativa do período fértil para usuárias que não utilizam método contraceptivo hormonal.

- Temas do grupo e aplicação: 30 das publicações analisadas, embora tivessem "Clue" em seu texto, não falavam propriamente do aplicativo, e sim de interações e dúvidas sobre os temas que este aborda acompanhamento do ciclo, muco, período fértil, menstruação, controle de temperatura, anticoncepcional e ovulação.

A Figura 16 apresenta uma visão geral dos itens codificados.

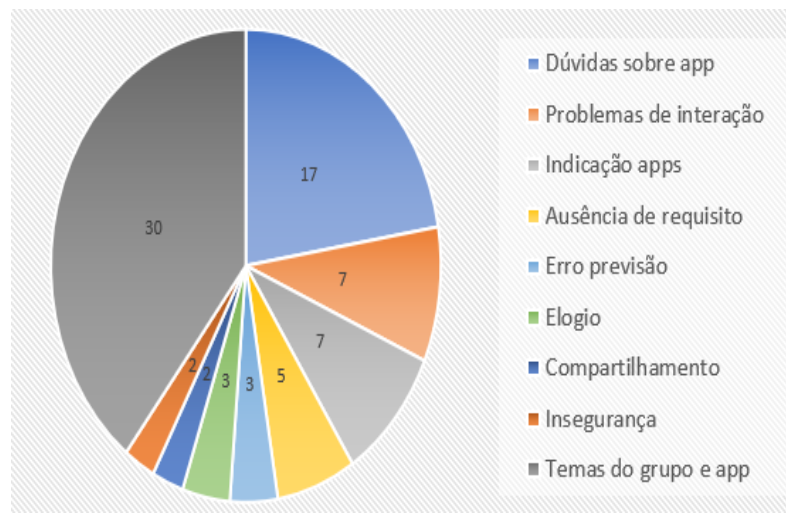

Figura 16. Gráfico de itens codificados.

Por fim, constatou-se que a grande maioria das citações da aplicação no grupo eram de usuárias compartilhando casos e dúvidas referentes não a aplicação em si, mas em sua utilização no contexto saúde da mulher.

\section{DISCUSSÃO}

Ao realizar o agrupamento dos dados de ambas avaliações, o grupo percebeu muitos aspectos em comum. Durante a Avaliação Heurística, notamos problemas por falta de informações, como na tela inicial onde são mostrados os dados do ciclo atual e foram constatadas reclamações referentes ao mesmo problema no grupo observado na Netnografia.

Diferenças entre calendários de acordo com o sistema operacional puderam ser notadas, o que acaba por desfavorecer as usuárias de Android, mostrando menos informações do que o calendário presente para o sistema operacional iOS. Na Netnografia, houve, também, grande número de reclamações quanto às informações (ou falta delas) nesta visão do aplicativo. A ausência de botões com finalidades específicas também foi uma constatação presente tanto na Avaliação Heurística quanto na Netnografia.

No que tange ao compartilhamento de informações, seja entre usuárias, entre aplicativos com o mesmo intuito ou na mudança de aparelhos celulares, o grupo notou que houveram vários problemas e reclamações, sendo uma funcionalidade importante que merece atenção redobrada pelo grupo responsável pelo aplicativo.

Algumas usuárias mostraram-se insatisfeitas com as previsões. Por mais que o aplicativo se utilize de dados anteriores para previsões de período menstrual, período fértil e período de TPM, o mesmo não especifica o tempo necessário para a sua própria adaptação ao ciclo da usuária, sendo um problema considerável, já que muitas das usuárias presentes no grupo o utilizam pois não fazem o uso de nenhum método contraceptivo hormonal e contam com estas previsões para seus planejamentos. Outro ponto importante é que, quando há a utilização de um método contraceptivo hormonal, o aplicativo não faz a previsão de período de TPM, apenas registra o período menstrual da usuária. Com isso em mente, o grupo acredita que poderia haver uma explicação no cadastro inicial de informações, alertando que não há esse tipo de dado quando se utiliza contraceptivos. Ao final do agrupamento e análise dos dados coletados, o grupo constatou que o aplicativo é útil para explicar o funcionamento do ciclo para usuárias que não possuem conhecimento prévio, mas deixa a desejar em alguns pontos de ajuda ao usuário na hora de utilizar o sistema.

De maneira geral, os problemas identificados têm como principais causas a falta de informação sobre as funcionalidades ou de um guia sobre como realizar as ações dentro do sistema. Uma das sugestões do grupo para resolver isso é de se implementar, dentro do aplicativo, um conjunto de artefatos que, de alguma forma, consiga deixar mais explícito quais ações podem ser realizadas em cada tela e como executá-las (como um tutorial). Sugerimos, também, tornar mais compreensível qual o objetivo dos botões na realização de cada funcionalidade (usando imagens mais representativas ou, até, explicando de forma textual). O aplicativo apresenta (visualmente) uma grande preocupação com o usuário, mas ainda existem essas questões citadas acima que acabam atrapalhando na usabilidade do Clue.

\section{CONSIDERAÇÕES FINAIS}

Para a elaboração deste trabalho, a interação entre membros do grupo foi fundamental. Como equipe multidisciplinar, foi importante mantermos uma comunicação ativa sobre as etapas do processo, assim como mantermos uma colaboração constante. Mesmo sendo alunas de cursos diferentes, e a maioria se conhecendo e trabalhando juntas pela primeira vez, o objetivo comum fez com que o processo de levantamento de dados e análise fosse bastante fluído.

Para a Avaliação Heurística, as três avaliadoras não só fizeram suas análises individuais como estiveram presencialmente fazendo a consolidação, o que trouxe mais pontos de vistas e enriqueceu a entrega. No que tange a Netnografia, embora uma aluna tenha sido a pesquisadora atuante na comunidade, também houve interação entre 
todas para discutir os pontos analisados e analisar as intersecções entre ambas as abordagens de investigação em IHC. O grupo avalia o Clue como um aplicativo extremamente importante no contexto de saúde da mulher, sistemas assim acabam estimulando o cuidado com a saúde e isso é essencial para o ser humano. Mesmo com os seus problemas de usabilidade (botões sem finalidades explícitas, falta de informação, etc.), nós consideramos que o Clue proporciona uma gama de informações bem completas, assim como achamos a sua aparência bem simples e intuitiva.

Por fim, o presente estudo fez com que adquiríssemos vivência na área de pesquisa acadêmica, assim como serviu de oportunidade para aprofundarmos e enriquecermos nosso conhecimento sobre metodologias de análise em IHC.

\section{REFERÊNCIAS BIBLIOGRÁFICAS}

1. John W. Creswell. 2014. Investigação Qualitativa e Projeto de Pesquisa: escolhendo entre cinco abordagens. Penso Editora.

2. Carolina Branco de Castro Ferreira. 2015.

Feminisms on the web: lines and forms of action in contemporary feminist debate. cadernos pagu. 44 (janeiro-junho 2015), 199-228.
3. Robert V. Kozinets. 2014. Netnografia. Realizando Pesquisa Etnográfica Online. Penso Editora.

4. Jakob Nielsen. 1993. Usability Engineering. Academic Press.

5. Jakob Nielsen. 1994. Heuristic Evaluation. In Usability Inspection Methods. In Robert Mack and Jakob Nielsen (eds.). John Wiley \& Sons, New York, 25-62.

6. Fernanda de Brito Mota Rocha. 2017. A quarta onda do movimento feminista: o fenômeno do ativismo digital. Dissertação de Mestrado. Universidade do Vale do Rio dos Sinos, São Leopoldo, RS. 